\title{
Cell surface abnormality in clones of skin fibroblasts from a carrier of Duchenne muscular dystrophy
}

\author{
J HILLIER*, G E JONES†, H E STATHAM*, J A WITKOWSKI*, AND \\ V DUBOWITZ*
}

From * the Jerry Lewis Muscle Research Centre, Department of Paediatrics and Neonatal Medicine, Royal Postgraduate Medical School, London W12 OHS; and the Department of Biology, Queen Elizabeth College, London W8 7AH.

SUMMARY We have previously reported that skin fibroblasts from patients with Duchenne muscular dystrophy (DMD) have a lower intercellular adhesiveness than control cells, and that cells from carriers of DMD have normal adhesiveness instead of the expected intermediate value. We have now cloned skin fibroblasts from a carrier of DMD (subject AS) who is also heterozygous for G6PD B/G6PD Mediterranean and determined the intercellular adhesiveness and G6PD phenotypes of the clones. G6PD activity was determined using the 2d-G6P/G6P ratio method. Normal cells had a percentage utilisation of $7.31 \%$ and uncloned cells from AS a value of $25 \cdot 16 \%$. Of 16 clones, 15 had normal values (mean $8 \cdot 72 \%$ ) while one clone was G6PD Med with a value of $57 \cdot 5 \%$. Mean intercellular adhesiveness of normal and uncloned cells from AS were 2.95 and 2.90 respectively. Of 11 clones tested, nine had normal values of adhesiveness (mean 3.1) and all these clones were G6PD B. The single G6PD Med clone had a value of $0 \cdot 88$, compared with 1.39 for DMD cells. We have no explanation at present for the single clone that was G6PD B but DMD-like on aggregation.

Duchenne muscular dystrophy is a severe, degenerative disorder of muscle ${ }^{1}$ that may result from some abnormality of the plasma membrane. ${ }^{2}$ Measurements of aggregation kinetics using Couette viscometry ${ }^{3}$ have shown that skin fibroblasts from patients with Duchenne muscular dystrophy (DMD) have intercellular adhesiveness approximately $40 \%$ that of normal cells. ${ }^{45}$

As a result of $\mathrm{X}$ chromosome inactivation, ${ }^{6}$ cultures of skin fibroblasts from carriers of DMD should be composed of cells of low (DMD) and high (normal) adhesiveness. These cultures should give intermediate values of adhesiveness ${ }^{7}$ but, as we have shown previously, carrier cells have normal values. ${ }^{8}$ We suggested that this result could be explained (a) if the DMD locus escaped inactivation so that a normal gene was active in all cells, or (b) if there was cooperation between normal and DMD cells in the cultures, or (c) if the cultures contained an excess of normal cells as a result of selection in vivo or in vitro

Received for publication 23 December 1983

Accepted for publication 8 June 1984. against cells expressing the $\mathrm{X}$ chromosome bearing the DMD gene.

We have now tested these possible explanations by determining the intercellular adhesiveness of clones of skin fibroblasts from a carrier of DMD who is also heterozygous for another $\mathrm{X}$ linked gene, glucose-6-phosphate dehydrogenase Mediterranean variant (G6PD Med).

\section{Methods}

Cells from carrier AS were obtained through the kindness of Dr T Webb and Professors A Cao and $\mathrm{J} \mathrm{H}$ Edwards. Cells from AS were plated at densities of 25 and 50 cells per $60 \mathrm{~mm}$ diameter petri dishes in Ham's F10 medium (Earle's salts) supplemented with $15 \%$ fetal calf serum, $50 \mathrm{IU} / \mathrm{ml}$ penicillin, and $50 \mu \mathrm{g} / \mathrm{ml}$ streptomycin. Individual clones were isolated using glass cylinders and subsequent passaging was carried out using Eagle's MEM with Hank's salts containing $10 \%$ fetal calf serum and $10 \mathrm{mmol} / \mathrm{l}$ Hepes buffer. There was considerable variability in clonal cell morphology and growth, and many 100 
isolated clones failed to grow for more than a maximum of two or three passages.

Cell aggregation kinetics were measured as described previously. ${ }^{8}$ Briefly, confluent monolayers of cells were washed with calcium- and magnesiumfree Hank's balanced salt solution and gently agitated at room temperature with $2.5 \mathrm{ml}$ of $0.25 \%$ trypsin solution for 20 minutes. Cells were collected, washed once with calcium- and magnesium-free saline, and resuspended at a concentration of $0.5 \times$ 10 cells per $\mathrm{ml}$ in Eagle's MEM containing $5 \%(\mathrm{w} / \mathrm{v})$ Ficoll 400 (Pharmacia). Single cells made up more than $90 \%$ of the total particle concentration. Aggregations were performed at $37^{\circ} \mathrm{C}$ using Couette viscometers set to a shear rate of $10 \mathrm{~s}^{-1}$. All samples were assayed blind.

G6PD phenotype was determined according to the 2d-G6P/G6P ratio method of Ferraris et al. ${ }^{9}$ Washed and trypsinised pellets of cells were lysed and sonicated in $10 \mathrm{mmol} / 1$ Tris- $\mathrm{HC} 1$ buffer, $\mathrm{pH} 7 \cdot 6$, containing $1 \mathrm{mmol} / \mathrm{EDTA}, 0 \cdot 5 \% \mathrm{NP}-40,10 \mu \mathrm{mol} / \mathrm{l}$ NADP, and $1 \mathrm{mmol} / \mathrm{l}$ E-amino-n-caproic acid. Aliquots for protein determination were precipitated with acetone and the protein precipitate dissolved in $1 \mathrm{~mol} / \mathrm{l} \mathrm{NaOH}$ containing $0.4 \%$ SDS. G6PD activity was measured according to the standardised method of the World Health Organization $^{10}$ and the relative utilisation of analogue/substrate was calculated as a percentage. All samples were assayed blind.

\section{Results}

Results of the G6PD assays are presented in the figure and the table. Uncloned cultures from AS had a percentage utilisation of $2 \mathrm{~d}-\mathrm{G} 6 \mathrm{P}$ of $25 \cdot 16 \% \pm 4.96$ SEM $(n=7)$ compared with a value of $7 \cdot 31 \% \pm 0.49$ $(n=26)$ for 15 normal subjects. (This group includes both control and DMD cells.) The clones isolated from cultures of AS could be divided into two groups on the basis of the $2 \mathrm{~d}-\mathrm{G} 6 \mathrm{P} \%$ utilisation. Of 16 clones, 15 had a mean value of $8 \cdot 72 \% \pm 0 \cdot 44$, not different from normal values but significantly less than uncloned cells from AS. One clone had a mean utilisation of $57 \cdot 75 \% \pm 5 \cdot 14(n=7)$, significantly greater than uncloned cells and the normal clones.

Results of determinations of intercellular adhesiveness are also given in the figure and the table. The mean intercellular adhesiveness of uncloned cells from AS was 2.90 $\pm 0.23 \operatorname{SEM}(n=8)$, not significantly different from the mean value for normal cells, $2.95 \pm 0.72(n=18)$. Clones from AS could again be separated into two groups: nine of 11 clones had a mean value of $3 \cdot 10 \pm 0 \cdot 130$, not significantly different from the value for normal cells or for uncloned cells from AS. The remaining two

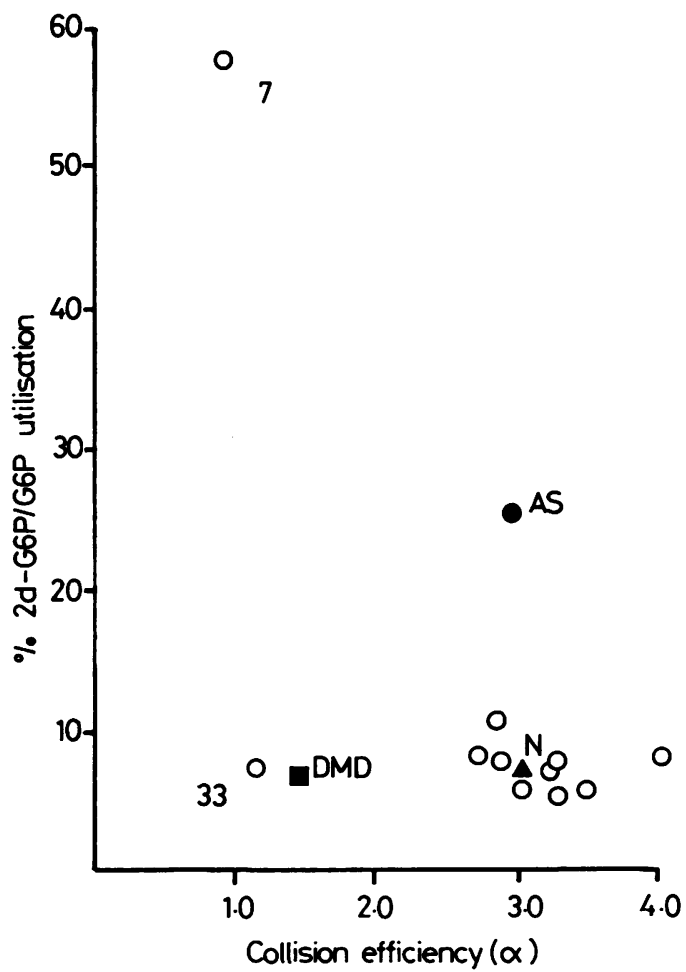

FIGURE $2 d-G 6 P / G 6 P \%$ utilisation of cells plotted against intercellular adhesiveness $(\alpha)$. High $2 d-G 6 P / G 6 P$ values indicate G6PD Med phenotype. High values of $\alpha$ indicate high (normal) adhesiveness. Normal skin fibroblasts ( $\mathbf{\Delta}$ ), skin fibroblasts from DMD patients ( $\square$ ), uncloned cultures of AS (O), clones of AS cells (O). Clones 7 and 33 are marked.

TABLE G6PD phenotype and intercellular adhesiveness of clones.

\begin{tabular}{lcl}
\hline Cells & $2 d-G 6 P / G 6 P$ ratio $(\%)$ & Collision efficiency \\
\hline Normal & $7 \cdot 31 \pm 0 \cdot 49(26)$ & $2 \cdot 95 \pm 0 \cdot 72(18)$ \\
DMD & $*$ & $1 \cdot 39 \pm 0 \cdot 11(27)$ \\
AS (uncloned) & $25 \cdot 16 \pm 4 \cdot 96(7)$ & $2 \cdot 90 \pm 0 \cdot 23(8)$ \\
Clone 2 & $8 \cdot 28 \pm 1 \cdot 06(4)$ & $3 \cdot 16 \pm 0 \cdot 08(4)$ \\
7 & $57 \cdot 75 \pm 5 \cdot 14(7)$ & $0 \cdot 88 \pm 0 \cdot 10(4)$ \\
8 & $8 \cdot 80 \pm 0 \cdot 93(6)$ & $2 \cdot 64$ \\
9 & $7 \cdot 16 \pm 1 \cdot 02(4)$ & NT \\
12 & $9 \cdot 25 \pm 1 \cdot 20(4)$ & NT \\
14 & $8 \cdot 00 \pm 0 \cdot 98(6)$ & $3 \cdot 13$ \\
15 & $5 \cdot 98 \pm 0 \cdot 39(4)$ & $3 \cdot 18$ \\
18 & $11 \cdot 38 \pm 2 \cdot 98(4)$ & $2 \cdot 76$ \\
19 & $9 \cdot 80 \quad(2)$ & NT \\
20 & $12 \cdot 30 \pm 2 \cdot 21(4)$ & NT \\
26 & $7 \cdot 19 \pm 1 \cdot 84(6)$ & $2 \cdot 95$ \\
33 & $7 \cdot 50 \pm 0 \cdot 82(4)$ & $1 \cdot 11 \pm 0 \cdot 07(4)$ \\
52 & $8 \cdot 45 \pm 0 \cdot 60(3)$ & NT \\
54 & $6 \cdot 50 \quad(2)$ & $3 \cdot 39$ \\
56 & $8 \cdot 62 \pm 1 \cdot 19(3)$ & $3 \cdot 93$ \\
57 & $8 \cdot 49 \quad(2)$ & $2 \cdot 80$
\end{tabular}

*For the G6PD assay, DMD cells were considered normal and included in the normal group. Values are means; the SEM is given except where fewer than three determinations were made. Number of samples is given in parentheses. NT $=$ not tested. 
clones had values of $0 \cdot 88 \pm 0 \cdot 10(n=4)$ and $1 \cdot 11 \pm$ $0.07(n=4)$, not significantly different from the mean value of $1.39 \pm 0 \cdot 11(n=27)$ for DMD cells.

\section{Discussion}

Only one clone out of 16 was found to have a G6PD Med phenotype. It is possible that the G6PD assay was performed on a selected population not representative of the uncloned cultures. Because large numbers of cells were required for the adhesion assay, the G6PD assay was performed on only those clones that grew well, and one or other of the two cell types present may have been better able to grow at clonal densities. Furthermore, the disproportion of Med and normal cells in the uncloned cultures may not be as extreme as indicated by the $1 / 16$ proportions of the clones. Because of the small sample size, this result could have been obtained by chance from a population in which the ratio of the two cell types was in fact $1 / 4$. Nevertheless, wide deviations from the expected 1:1 ratio have also been reported in studies of the Lesch-Nyhan ${ }^{11}$ and testicular feminisation ${ }^{12}$ syndromes.

The normal intercellular adhesiveness data obtained with uncloned carrier cells ${ }^{8}$ could be explained if the DMD locus were not inactivated. However, although $\mathrm{XgA}^{13}$ and $\mathrm{STS}^{14}$ escape inactivation, they are a considerable distance from the DMD locus believed to be at Xp21. ${ }^{15}$ Furthermore, inactivation of the DMD gene is the most satisfactory explanation for the variable expression of the disorder in carriers ${ }^{16}$ and in a pair of identical twins who are carriers of DMD. ${ }^{17}$ The data in the table and the figure show that, with one exception, there is concordance between expression of the G6PD phenotype and intercellular adhesiveness $(\alpha)$ for clones from subject AS: G6PD positive clones have normal values of $\alpha$ while the G6PD Med clone has a low value of $\alpha$.

Two other reports have been published recently that claim to demonstrate the occurrence of $\mathrm{X}$ chromosome inactivation in skin fibroblasts and muscle cells from carriers of DMD. Ionasescu et al ${ }^{18}$ have reported data describing the occurrence of two types of skin fibroblast clone, one with high (DMDlike) and one with normal incorporation of hydroxyproline. Unfortunately they did not give the proportions of the normal and mutant clones found. Thompson et al ${ }^{19}$ have examined cultures of muscle cells from DMD heterozygotes for the phenomenon of 'clustering', described by them in DMD patient muscle cultures (but see reference 20 for contradictory data). However, they did not use clones of cells from carriers, but found that cultures of seven out of
14 carrier biopsies showed clustering. Their conclusion that they have demonstrated $\mathrm{X}$ chromosome inactivation in DMD carriers depends on the assumption that the patch sizes of normal and DMD cells in these carriers is large relative to the biopsy size.

Clone 33 is exceptional in that it is unequivocally G6PD positive but has unequivocally low intercellular adhesiveness characteristic of DMD. Preliminary karyological analysis (Dr Daker, Paediatric Research Unit, Guy's Hospital) indicates that there is no major chromosomal structural abnormality to account for this. Recent studies of the expression of recessive alleles in retinoblastoma have found evidence for what may be an example of in vivo mitotic recombination, ${ }^{21}$ and we may have detected a similar phenomenon in a somatic cell in vitro. Alternatively, reactivation of the G6PD B locus on the inactivated $\mathrm{X}$ chromosome carrying the (normalG6PD B) loci would result in cells of the clone 33 phenotype. However, the G6PD phenotype of clone 33 cells appeared completely normal, although Migeon et $a l^{22}$ found that the derepressed locus produced only half the enzyme subunits produced by the normally active locus.

For this carrier, the high proportion of G6PD+ve/ normal adhesiveness clones would account for the normal aggregation of her uncloned cells. It is unfortunate that we are unable to continue cloning experiments with this carrier as her cells have been difficult to grow at clonal densities. Our current data do not exclude cooperation between the normal and DMD cells in an uncloned carrier culture as the explanation for the normal aggregation of cells from other carriers. ${ }^{8}$

The results obtained in the present study are particularly important because we can now use measurements of intercellular adhesiveness in obligatory heterozygotes for DMD who do not carry a marker for a second $\mathrm{X}$ linked heterozygosity. Polymorphic differences between these clones will be restricted to $\mathrm{X}$ linked loci, that is, to about $6 \%$ of the length of the genome. ${ }^{23}$ Differing autosomal loci may be active in the two sets of clones as a result of the expression of the DMD locus in one set of clones, but the total differences between clones will be considerably reduced compared with those between genetically unrelated normal and DMD subjects. We are now searching for protein differences between such clones using two dimensional polyacrylamide gel electrophoresis. ${ }^{24}$

This work is based on an idea originally suggested by Dr K W Jones, University of Edinburgh, and was supported by grants from the Muscular Dystrophy Group of Great Britain and the Wellcome Trust. 


\section{References}

${ }^{1}$ Dubowitz V. Muscle disorders in childhood. London: Saunders, 1979.

2 Jones GE, Witkowski JA. Membrane abnormalities in Duchenne muscular dystrophy. J Neurol Sci 1983;58:159-74.

3 Curtis ASG. The measurement of cell adhesiveness by an absolute method. J Embryol Exp Morphol 1969;22:305-22.

4 Jones GE, Witkowski JA. Reduced adhesiveness between skin fibroblasts from patients with Duchenne muscular dystrophy. $J$ Neurol Sci 1979;43:465-70.

5 Jones GE, Witkowski JA. Analysis of skin fibroblast aggregation in Duchenne muscular dystrophy. J Cell Sci 1981;48:291300.

${ }^{6}$ Lyon M. Gene action in the $\mathrm{X}$ chromosome of the mouse. Nature 1961;190:372-3.

7 Jones GE. Cell disposition and adhesiveness in the chick neural retina. J Embryol Exp Morphol 1977;40:253-8.

${ }^{8}$ Jones GE, Witkowski JA. A cell surface abnormality in Duchenne muscular dystrophy: intercellular adhesiveness of skin fibroblasts from patients and carriers. Hum Genet 1983;63:232-7.

9 Ferraris AM, Giuntini P, Galiano S, Gaetani GF. 2-deoxyglucose-6-phosphate utilization in the study of glucose-6phosphate dehydrogenase mosaicism. Am J Hum Genet 1981;33:307-13.

${ }^{10}$ World Health Organization. Standardization of procedures for the study of glucose-6-phosphate dehydrogenase. WHO Tech Rep Ser 1967;366:1-53.

11 Migeon BR. Studies of skin fibroblasts from 10 families with HGPRT deficiency, with reference to X-chromosomal inactivation. Am J Hum Genet 1971;23:199-210.

12 Elawady MK, Allman DR, Griffin JE, Wilson JD. Expression of a mutant androgen receptor in cloned fibroblasts derived from a heterozygous carrier for the syndrome of testicular feminization. Am J Hum Genet 1983;35:376-84.

13 Fialkow PJ. X-chromosome inactivation and the $\mathrm{Xg}$ locus. $\mathrm{Am} \mathrm{J}$ Hum Genet 1970;22:460-3.

14 Shapiro CJ, Mohandas T, Weiss R. Non-inactivation of an $\mathrm{X}$-chromosome locus in man. Science 1979;204:1224-6.
15 Jacobs PA, Hunt PA, Mayer M, Bart RD. Duchenne muscular dystrophy (DMD) in a female with an X/autosome translocation: further evidence that the DMD locus is at Xp21. Am J Hum Genet 1981;33:513-8.

16 Yoshioka M. Clinically manifesting carriers in Duchenne muscular dystrophy. Clin Genet 1981;20:6-12.

17 Gomez MR, Engel AG, Dewald G, Peterson HA. Failure of inactivation of Duchenne muscular dystrophy X-chromosome in one of female identical twins. Neurology (Minneap) 1977;27:537-41.

${ }^{18}$ Ionasescu V, Ionasescu R, Searby C. Fibroblast clones for detection of Duchenne carriers. N Engl J Med 1983;309:51-2.

19 Thompson EJ, Yasin R, Lake BD, Cavanagh NPC. Possible manifestation of the dystrophic $\mathrm{X}$ chromosome in muscle cultures from carriers of Duchenne muscular dystrophy. Exp Neurol 1983;79:720-8.

${ }^{20}$ Ecob-Johnston MS, Brown AE. Cluster formation in monolayer cultures of normal and diseased human muscle. Exp Neurol 1981;71:390-7.

${ }^{21}$ Cavenee WK, Dryja TP, Phillips RA, et al. Expression of recessive alleles by chromosomal mechanisms in retinoblastoma Nature 1983;305:779-84.

22 Migeon BR, Wolf SF, Mareni C, Axelman J. Derepression with decreased expression of the G6PD locus on the inactive $X$ chromosome in normal human cells. Cell 1982;29:595-600.

${ }^{23}$ McKusick V. Mendelian inheritance in man. Baltimore: Johns Hopkins University Press, 1978.

24 Burghes AHM, Dunn MJ, Statham HE, Dubowitz V. Analysis of cultured skin fibroblasts from patients with Duchenne muscular dystrophy using electrophoretic techniques. In: Allen RC, Arnaud P, eds. Electrophoresis 81. Berlin: Walter de Gruyter, 1981:285-308.

Correspondence and requests for reprints to Dr J A Witkowski, Jerry Lewis Muscle Research Centre, Royal Postgraduate Medical School, Ducane Road, London W12 0HS. 